\title{
Reproducibility of measurements of exhaled NO, and cell count and cytokine concentrations in induced sputum
}

\author{
M. Purokivi*, J. Randell*, M-R. Hirvonen**, H. Tukiainen*
}

Reproducibility of measurements of exhaled NO, and cell count and cytokine concen-
trations in induced sputum. M. Purokivi, J. Randell, M-R. Hirvonen, H. Tukiainen. (C)ERS Journals Ltd 2000.

ABSTRACT: Sputum induction is a noninvasive, well-tolerated method for studying airway inflammation. When induction with hypertonic saline is repeated at short time-intervals $(<\mathbf{2 4} \mathbf{~ h})$, the cell profile of sputum has not been reproducible. To determine the proper interval between sampling cell profiles and cytokine contents of sputum samples that had been induced $48 \mathrm{~h}$ apart, were compared. In addition, the inducible nitric oxide synthase (iNOS) expression of sputum cells was compared to the levels of exhaled nitric oxide (NO).

Sputum induction and measurement of exhaled NO was performed in 31 healthy nonatopic volunteers. Cell differentials were counted. Concentrations of interleukin (IL)-4, IL-6, tumour necrosis factor (TNF) $\alpha$, eosinophil cationic protein (ECP) were measured in sputum supernatant, and iNOS was determined.

Reproducibility of cell counts was high $(r=0.836$ total cells, $r=0.762$ neutrophils, $r=0.966$ eosinophils, $r=0.742$ macrophages). IL-4 ( $r=0.398)$, IL-6 $(r=0.566)$, TNF $\alpha$ $(r=0.658)$ and ECP $(r=0.501)$ were also less reproducible in healthy volunteers. Consistent with the low levels of NO in the exhaled air $(18.5 \pm 2.6 \mathrm{ppb}$ and $19.3 \pm 2.8$ parts per billion (ppb) on the two study days, $r=0.976, p=0.0000$ ), expression of iNOS was not detected.

In conclusion, in healthy subjects, induced sputum cell counts are reproducible. Even though the success rate in nonatopic populations is relatively low, sputum induction appears to be a valid method for detecting inflammatory changes within the airways, when being performed $48 \mathrm{~h}$ apart.

Eur Respir J 2000; 16: 242-246.
*Dept of Respiratory Medicine, Kuopio University Hospital, Kuopio, Finland, **Laboratory of Toxicology, National Public Health Institute, Kuopio, Finland.

Correspondence: M. Purokivi

Dept of Respiratory Medicine

Kuopio University Hospital

P.O. Box 1777

FIN-70211 Kuopio

Finland

Fax: 35817172683

Keywords: Inducible nitric oxide synthase reproducibility

sputum induction

Received: September 301999

Accepted after revision April 142000

This work was supported by the Academy of Finland and the Finnish Antituberculosis Association.
There has been wide interest in developing noninvasive methods to determine lower airway inflammation in different respiratory disorders. Measurement of inflammatory mediators in induced sputum provides a direct method to investigate airway inflammation in different respiratory conditions including asthma. Sputum induction by nebulized hypertonic saline has been found to be safe and well tolerated [1-3]. However, the saline inhalation affects the production of inflammatory markers, since neutrophilia and loss of macrophages has been reported in samplings repeated within $24 \mathrm{~h}$ [4]. This suggests that a longer time interval is required between two samplings of induced sputum, when it is used for the evaluation of allergen challenge. Thus, the time interval in which possible effects of saline inhalation disappear, needs to be defined.

Defining the cytokine profile in induced sputum could widen the view to inflammatory state of lower respiratory tract. Previously the attempts to measure cytokines by using bronchoalveolar lavage samples have failed because of dilution caused by the large volume of saline needed for sampling [5]. In sputum induction this problem is avoided, at least when low volume of nebulized saline is used [6].

Since not all patients are able to produce sputum, despite induction with hypertonic saline, other noninvasive methods to detect airway inflammation are needed. One of the most promising is the measurement of exhaled nitric ox- ide (NO) by a chemiluminescence analyser [7]. NO plays an important role as an immune defence molecule. The excessive production of $\mathrm{NO}$ by inducible nitric oxide synthase (iNOS) promotes the classical signs of inflammation and causes tissue injury. Changes in exhaled NO correlate with the number of eosinophils and increased eosinophilic cationic protein (ECP) values in induced sputum $[8,9]$. The role of proinflammatory cytokines in the upper respiratory tract has previously been discussed in relation to indoor air problems as well as in relation to viral infection. Therefore, a more comprehensive spectrum of inflammatory markers, than those referring only to allergy, should be assessed from induced sputum, if the symptoms of the patient refer to inflammation but are not caused by asthma or immunoglobulin (Ig)E-mediated allergic reaction.

The aim of the present study was to evaluate the effect of saline inhalation on cell counts and cytokine concentrations in induced sputum repeated $48 \mathrm{~h}$ apart. The reproducibility of total cell count, cell differentials and ECP as well as concentrations of interleukin 4 (IL)-4, IL-6 and tumour necrosis factor (TNF) $\alpha$ in the supernatant of induced sputum were analysed in healthy volunteers. Moreover, the reproducibility of NO measurements by chemiluminescence analyser were studied, and the expression of iNOS in the cells of induced sputum was compared to levels of exhaled NO. 


\section{Methods}

\section{Subjects}

Thirty-one healthy, non-atopic volunteers, 25-58 (mean 43) yrs of age, selected from the staff at the Dept of Respiratory Medicine and Dept of Clinical Chemistry, were studied. They completed a questionnaire concerning their current health, previous inflammatory diseases, possible respiratory symptoms, occupational and housing conditions and smoking habits. None of them were using inhaled medication. The study was conducted according to the principles of the Declaration of Helsinki and it was approved by the Ethical Committee of the Kuopio University Hospital.

\section{Study design}

The subjects attended the laboratory twice, $48 \mathrm{~h}$ apart at the same time of the day. On the first visit they completed the health questionnaire, and peak expiratory flow rate (PEFR) (Wright Peak Flow meter; Airmed Ltd, Harlow, UK) [10] and exhaled NO were measured. After inhalation of salbutamol, sputum was induced. On the second visit the same measurements were repeated.

\section{Sputum induction and processing}

Peak expiratory flow rate (PEFR) was performed before and after the sputum induction, for safety reasons. The subjects inhaled two puffs of salbutamol (Buventol Easyhaler(R) $100 \mu \mathrm{g} \cdot \mathrm{dos}^{-1}$ ), followed by inhalation of $5 \mathrm{~mL}$ nebulized, hypertonic (4\%) saline for 15-20 min [11]. Saline solution was nebulized by an ultrasonic nebulizer, particle size $7.5 \mu \mathrm{m}$ (Omron Ul; Omron Healthcare GmbH, Hamburg, Germany). The collected sputum samples were examined within $2 \mathrm{~h}$ to avoid cell destruction [12]. Briefly, sputum plugs originating from the lower respiratory tract were separated and weighed. Freshly prepared dithireitol (DTT), (Sputolysin, Calbiochem corp., San Diego, CA, USA) was diluted in distilled water (1:10), and this solution was added to the sputum in a volume equal to two times the weight of the sputum portion [12]. Sputum was then shaken in a water bath at $37^{\circ} \mathrm{C}$ for $15 \mathrm{~min}$. To ensure homogenization the sputum-DTT mixture was mixed using a vortex for $15 \mathrm{~s}$ every $5 \mathrm{~min}$. This suspension was further diluted with phosphate buffered saline (Dulbecco's phosphate buffered saline (D-PBS); Life Technologies Ltd, Paisley, UK) in a volume equal to the sputum plus DTT. Then the suspension was filtered through a $41 \mu \mathrm{m}$ nylon gauze (Millipore corporation, Badford, MA, USA) to remove mucus and was centrifuged $790 \times g$ for $10 \mathrm{~min}$. Total cell count (TCC) and cell viability (trypan blue exclusion method) were determined by using a haemocytometer. The supernatant was aspirated and frozen at $-70^{\circ} \mathrm{C}$.

\section{Biochemical analyses}

ECP $\left(\mu \mathrm{g} \cdot \mathrm{L}^{-1}\right)$ was analysed by radioimmunoassay (RIA, Pharmacia \& Upjohn, Uppsala, Sweden). Cytokines were analysed using human IL-6, IL-4 and TNF $\alpha$ Duoset enzyme-linked immunosorbent assay (ELISA)-kits (Genzyme, Cambridge, MA, USA). The samples were analysed by ELISA reader (iEMS Reader MF, Labsystems, Helsinki, Finland) at a wavelength of $450 \mathrm{~nm}$. Cytokine concentrations of samples were calculated by interpolating absorbances of samples to the standard curve. The detection limits for the ELISA were 2-5 pg.L iNOS was measured by Western blot analyses with antibody against iNOS (130 kDa) [13].

\section{Cytospin}

The cell pellet was resuspended in D-PBS to reach concentration of $1 \times 10^{6}$ cells $\cdot \mathrm{mL}^{-1}$. The cell suspension was centrifuged (Shandon, Life Sciences International Ltd, Cheshire, UK) at 450 revolutions per min (rpm) for 6 min. The slides were fixed by ethanol and stained by MayGrünwald Giemsa for cell differential count from 500 cells. Only samples with cell viability $>50 \%$ and squamous cell contamination $<20 \%$ were considered adequate [11].

\section{Measurement of exhaled nitric oxide}

Exhaled NO was measured by a chemiluminescence analyser (Sievers Model 280 NOA; Sievers Instruments, Inc., Boulder, CO, USA) according to the European Respiratory Society (ERS) guidelines for the measurement of exhaled NO [14]. Subjects performed a slow vital capacity (VC) manoeuvre for $30 \mathrm{~s}$ against a fixed expiratory resistance, which eliminated contamination by nasal NO by closing the soft palate. The pressure level during exhalation was optimized by following the computer screen on-line to reach constant flow rate in exhale. Exhaled air was led through a nonrebreathing valve into a Teflon tubing system connected to the analyser. Recordings were performed by the single-breath programme, and they were seen on a computer screen on-line. The subjects gave three exhaled samples. The relative standard deviation (SD) between collected samples was expected to be $<10 \%$. The detection limit for NO was 1 part per billion (ppb). Measurements were made in the same laboratory under constant conditions. The chemiluminescence analyser was calibrated daily by using zero air and a certified concentration of NO.

\section{Statistics}

Reliability coefficients and Bland-Altman plots [15] were used to describe reproducibility and intrapatient correlation of NO measurements, cell counts and cytokines. It was expected that $95 \%$ of the differences between measures $<2$ SD. Exploratory data analyses revealed that the distribution of the TNF $\alpha$ values obtained in this study was not normal and therefore, logarithmic transformations were used to analyse the reliability coefficient. Differential cell counts are presented as geometric mean (range) except eosinophils which are presented as mean (range) due to their small number. Results of cytokine measurements are presented as mean \pm SEM. The statistical analyses were performed by using the SPSS/PC+ software package version 8.0 (SPSS Inc., Chicago, USA) and Bland-Altman plots were drawn by MedCalc software package version 4.2 (MedCalc Software, Mariakerke, USA). 


\section{Results}

\section{Sputum induction}

Twenty of the thirty-one healthy volunteers $(64 \%)$ succeeded in sputum production. One sample was rejected because of a low cell count ( $<500$ cells per cytospin) and one because it contained a high number of squamous cells $(>20 \%)$. Thus, statistical analyses of total cell count, cell differentials and biochemical markers were done with 18 sample pairs. No significant variability was noticed between PEFR values before and after sampling. The mean weight of sputum on the first measurement day was (mean \pm SEM) $356 \pm 78 \mathrm{mg}$ and on the second $360 \pm 61 \mathrm{mg}$. The mean cell viability was $86 \%$ and $82 \%$ after 0 and $48 \mathrm{~h}$ respectively.

\section{Cell differentials}

With the exception of lymphocytes, all cell types were highly reproducible (fig. 1). The reliability coefficients of total cell count and cell differentials are shown in table 1.
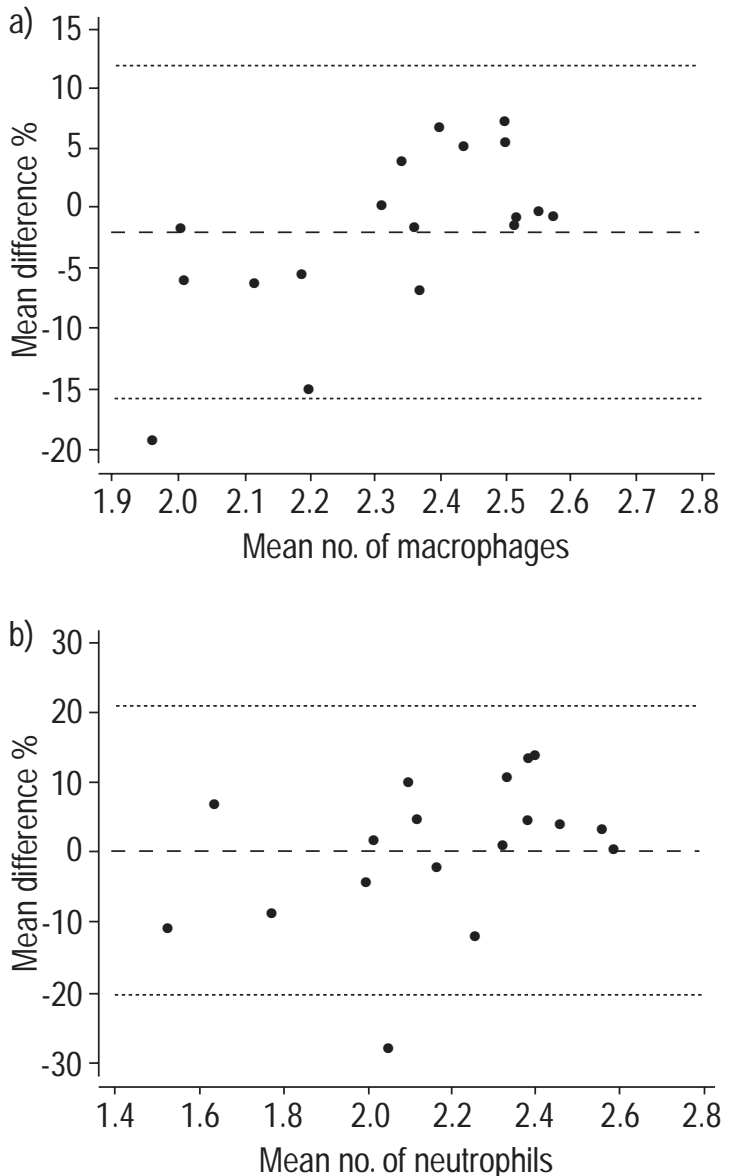

Table 1. - Reproducibility of differential cell count in induced sputum collected at 0 and $48 \mathrm{~h}$

\begin{tabular}{lccccc}
\hline & \multicolumn{2}{c}{ Cell number $10^{6}$ cells $\cdot \mathrm{L}^{-1}$} & & \\
\cline { 2 - 3 } & \multicolumn{1}{c}{$0 \mathrm{~h}$} & $48 \mathrm{~h}$ & $\mathrm{r}$ & $\mathrm{p}$ \\
\hline Total cells & $561(1699)$ & $440(1944)$ & 0.836 & $* * *$ \\
Macrophages & $203(334)$ & $221(278)$ & 0.742 & $* * *$ \\
Neutrophils & $152(373)$ & $148(350)$ & 0.762 & $* * *$ \\
Eosinophils & $2.0(90)$ & $1.5(55)$ & 0.966 & $* * *$ \\
Lymphocytes & $7.3(27)$ & $9.0(30)$ & 0.253 & \\
\hline
\end{tabular}

Values of 18 subjects are expressed as geometric mean (range) except $^{\#}$ : mean (range). ${ }^{* * *}$ : $\mathrm{p}<0.001$.

\section{Production of cytokines}

The measurements of IL- 6 ( $\mathrm{r}=0.567, \mathrm{p}=0.006$, fig. $2 \mathrm{a})$ TNF $\alpha$ ( $\mathrm{r}=0.658, \mathrm{p}=0.014$, fig. $2 \mathrm{~b})$, IL-4 $(\mathrm{r}=0.398, \mathrm{p}=$ 0.046 , fig. $2 \mathrm{~d}$ ) and $\mathrm{ECP}(\mathrm{r}=0.501, \mathrm{p}=0.003$, fig. $2 \mathrm{c})$ were also reproducible (table 2 ).

\section{Production of nitric oxide}

Exhaled NO was analysed from all 29 volunteers twice, $48 \mathrm{~h}$ apart. The mean NO levels were $18.5 \pm 2.6 \mathrm{ppb}$ and
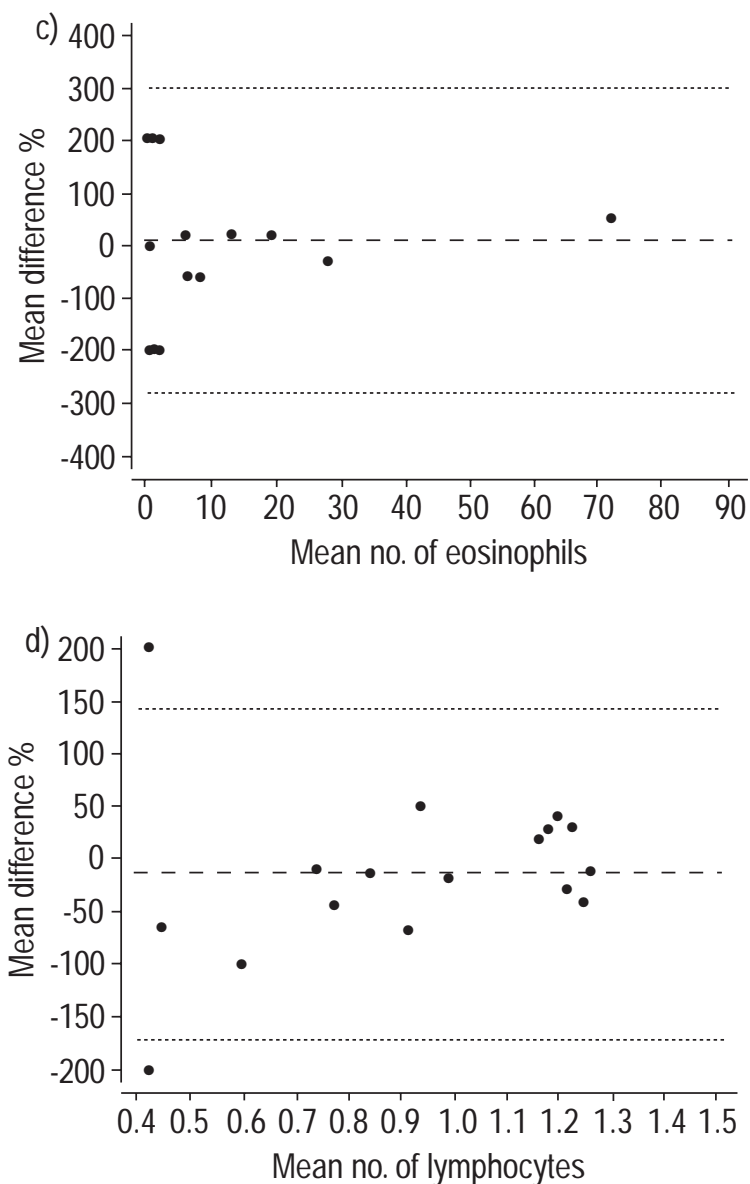

Fig. 1. - Reproducibility of differential cell counts: a) macrophages; b) neutrophils; c) eosinophils; d) lymphocytes in induced sputum (\%) mean $(---) \pm 1.96 \mathrm{SD}(\cdots)$. Repeatability of measurements is expressed as proposed by BLAND and ALTMAN [15] and it is expected that $95 \%$ of the differences between measures are $<2 \mathrm{sD}$. For each figure the differences of $\log$ values between $0 \mathrm{~h}$ and $48 \mathrm{~h}$ are plotted on vertical axis against the mean value of the two measurements. Due to small number of (or zero) eosinophils, they are expressed without log transformation. 

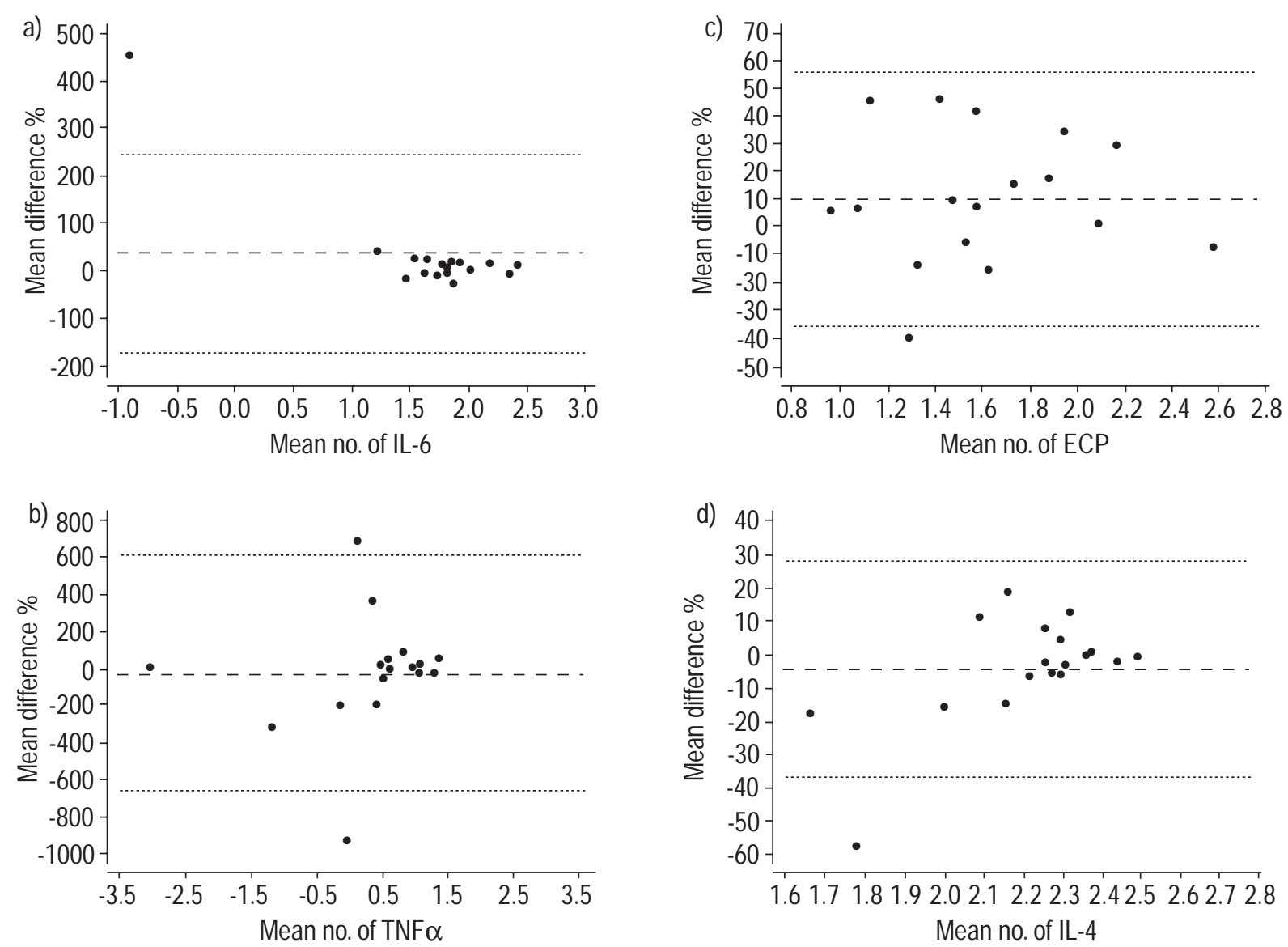

Fig. 2. - Reproducibility of cytokine measurements: a) interleukin (IL)-6 (pg.mL $\left.{ }^{-1}\right)$; b) tumour necrosis factor (TNF) $\alpha\left(\mathrm{pg} \cdot \mathrm{mL}^{-1}\right)$; c) IL-4 (pg $\left.\cdot \mathrm{mL}^{-1}\right)$; and d) eosinophil cationic protein (ECP) $\left(\mu \mathrm{g} \cdot \mathrm{L}^{-1}\right)$ in induced sputum $(\%)$, mean $(---) \pm 1.96 \mathrm{SD}(\cdots)$. Reproducibility of measurements is expressed as proposed by BLAND and Altman [15] and it is expected that $95 \%$ of the differences between measures are $<2$ SD.

$19.3 \pm 2.8$ ppb respectively on the two study days. ( $r=0.976$, $\mathrm{p}=0.0000$, fig. 3 ). Consistent with the low levels of $\mathrm{NO}$ in the exhaled air, expression of iNOS was not detected by Western blot analyses in the induced sputum samples (data not shown).

\section{Discussion}

The results demonstrate that systematic changes in cellular composition caused by saline inhalation $[4,16]$ can be avoided, when sputum induction is performed at least $48 \mathrm{~h}$ apart. In healthy volunteers the reproducibility of total cell count was high as well as that of eosinophils, neutrophils and macrophages. Consistent with previous studies the lymphocyte count was not reproducible [17]. The fairly small amount of saline used in the experimental

Table 2. - Interleukin (IL)-4, IL-6, tumour necrosis factor (TNF) $\alpha$ and eosinophilic cationic protein (ECP) in induced sputum collected at 0 and $48 \mathrm{~h}$

\begin{tabular}{lcccc}
\hline Time point & IL-4 & IL-6 & TNF $\alpha$ & ECP $^{\#}$ \\
\hline $0 \mathrm{~h}$ & $178 \pm 81.2$ & $113 \pm 107$ & $9.97 \pm 15.0$ & $80.3 \pm 94.0$ \\
$48 \mathrm{~h}$ & $189 \pm 65.7$ & $65.1 \pm 56.1$ & $5.24 \pm 5.39$ & $59.4 \pm 100$ \\
\hline
\end{tabular}

Data presented as mean \pm SEM, the units are $\mathrm{pg} \cdot \mathrm{mL}^{-1}$ unless otherwise stated. ${ }^{\#}$ : units $\mathrm{pg} \cdot \mathrm{L}^{-1}$. procedure to limit the inhalation time and to avoid the dilution of samples also enabled the measurements of cytokines in induced sputum. Despite a relatively short procedure of saline inhalation, $64 \%$ of healthy volunteers succeeded in sputum induction $48 \mathrm{~h}$ apart. The method was well tolerated with no changes in PEFR values measured before and after the saline inhalation.

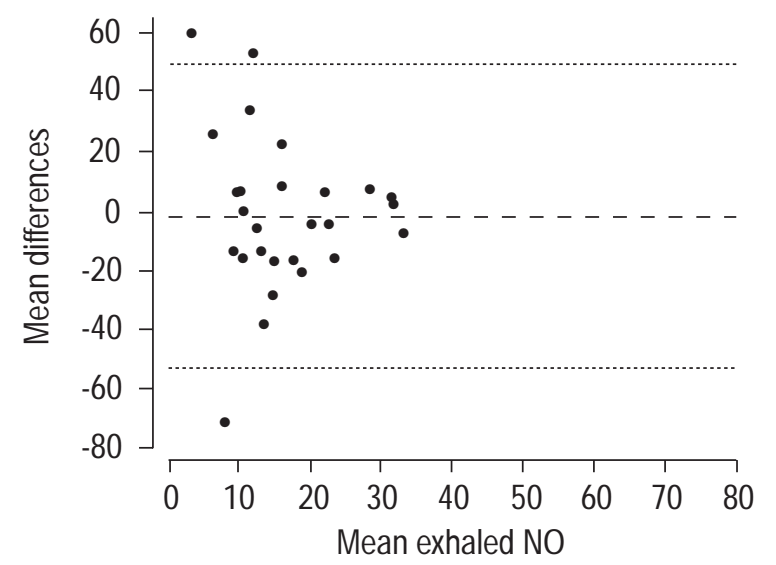

Fig. 3. - Reproducibility of measurements of exhaled NO. Reproducibility of measurements is expressed as proposed by BLAND and ALTMAN $[15]$ and it is expected that $95 \%$ of the differences between measures are $<2$ SD. 
According to the presented results the reproducibility of proinflammatory cytokines TNF $\alpha$ and IL- 6 in induced sputum is high in a $48 \mathrm{~h}$ interval. Moreover, the present results indicate that low concentrations of TNF $\alpha$ and IL-6 can be detected in induced sputum from healthy subjects. These cytokines are of interest in searching for new diagnostic tools because of their central role in airway inflammation. They may be involved in allergic inflammation as well as in symptoms caused by occupational or indoor air exposures [18].

The levels of IL- 4 were only low or moderate in the induced sputum of the healthy subjects in this study, however, they were still reproducible. In addition to low IL-4 concentrations, relatively small amounts of ECP in induced sputum suggest that the subjects did not suffer from IgE mediated allergy. The values at time point 0 were found to be slightly higher than those at $48 \mathrm{~h}$, but the difference did not reach statistical significance.

In the present study, the measurement of NO from exhaled air of healthy subjects was highly reproducible. In search for the plausible source of exhaled NO, it was demonstrated that no expression of iNOS was detectable in induced sputum cells of healthy subjects. This agrees with the previous study of HAMID et al. [19], where iNOS was detectable in epithelial biopsies of asthmatic subjects but not in those of healthy volunteers. TNF $\alpha$ is known to induce iNOS expression in human lung epithelial cells [20]. The low level of TNF $\alpha$ detected is in concordance with the absence of iNOS in induced sputum samples studied here. This suggests that NO concentrations measured from the subjects by a chemiluminescence analyser, were induced by constitutive nitric oxide synthase (cNOS). Together with the finding that no active inflammation is recognized, and the concentrations of proinflammatory cytokines and number of macrophages are low, the origin of NO measured is likely to be bronchial epithelium [21]. NO produced by cNOS is involved in physiological regulation of airway function, whereas NO produced by iNOS is involved in inflammatory diseases of the airways and in host defences against infection.

In conclusion, the cell count in induced sputum and measurement of exhaled nitric oxide are reproducible and valid methods in detecting the inflammatory changes, when sputum induction is performed $48 \mathrm{~h}$ apart. Cytokines can also be reliably determined from induced sputum. Expression of inducible nitric oxide synthase was not detected from the samples of healthy subjects, its measurement may be a helpful tool in studying inflammatory processes and the origin of the nitric oxide.

Acknowledgements. The authors wish to thank the volunteers from the Kuopio University Hospital for participating in the study. I.M. Penttilä is acknowledged for his valuable advice in sputum processing and statistical analyses. R. Tukiainen and H. Martikainen are acknowledged for their excellent technical assistance and M. Vahteristo, for help in statistical analyses.

\section{References}

1. De la Fuente PT, Romagnoli M, Godard P, Bousquet J, Chanez P. Safety of inducing sputum in patients with asthma of varying severity. Am J Respir Crit Care Med 1998; 157: 1127-1130.
2. Hunter CJ, Ward R, Woltmann G, Wardlaw AJ, Pavord ID. The safety and success rate of sputum induction using a low output ultrasonic nebuliser. Respir Med 1999; 93: 345-348.

3. Pin I, Gibson GG, Kolendowich R, et al. Use of induced sputum cell counts to investigate airway inflammation in asthma. Thorax 1992; 47: 25-29.

4. Nightingale JA, Rogers DF, Barnes PJ. Effect of repeated sputum induction on cell counts in normal volunteers. Thorax 1998; 53: 87-90.

5. Fahy JV, Wong H, Liu J, Boushey HA. Comparison of samples collected by sputum induction and bronchoscopy from asthmatic and healthy subjects. Am J Respir Crit Care Med 1995; 152: 53-58.

6. Thorn J, Rylander R. Inflammatory responses after inhalation of bacterial endotoxin assessed by the induced sputum technique. Thorax 1998; 53: 1047-1052.

7. Kharitonov SA, Yates D, Robbins RA, Logan-Sinclair R, Shinebourne EA, Barnes PJ. Increased nitric oxide in exhaled air of asthmatic patients. Lancet 1994; 343: 133135.

8. Chan-Yeung M, Obata H, Dittrick M, Chan H, Abboud R. Airway inflammation, exhaled nitric oxide, and severity of asthma in patients with western red cedar asthma. $A m J$ Respir Crit Care Med 1999; 159: 1434-1438.

9. Silvestri M, Spallarossa D, Frangova Yourukova V, Battistini E, Fregonese B, Rossi GA. Orally exhaled nitric oxide levels are related to the degree of blood eosinophilia in atopic children with mild-intermittent asthma. Eur Respir J 1999; 13: 321-326.

10. Quanjer PH, Lebowitz MD, Gregg I, Miller MR, Pedersen OF. Peak expiratory flow: conclusions and recommendations of a working party of the European respiratory society. Eur Respir J 1997; 10: Suppl. 24, 2S-8S.

11. Popov TA, Pizzichini MMM, Pizzichini E, et al. Some technical factors influencing the induction of sputum for cell analysis. Eur Respir J 1995; 8: 559-565.

12. Popov T, Gottschalk R, Kolendowicz R, Dolovich J, Powers P, Hargreave FE. The evaluation of a cell dispersion method of sputum examination. Clin Exp Allergy 1994; 24: 778-783.

13. Hirvonen M-R, Brune B, Lapetina EG. Heat shock proteins and macrophage resistance to the toxic effects ofnitric oxide. Biochem J 1996; 315: 845-849.

14. Kharitonov S, Alving K, Barnes PJ. Exhaled and nasal nitric oxide measurements: recommendations. Eur Respir $J$ 1997; 10: 1683-1693.

15. Bland MJ, Altman DG. Statistical methods for assessing agreement between two methods of clinical measurement. Lancet 1986; 307-310.

16. Holz O, Richter K, Jörres RA, Speckin P, Mucke M, Magnussen H. Changes in sputum composition between two inductions performed on consecutive days. Thorax 1998; 53: 83-86.

17. Spanevello A, Migliori GB, Sharara A, et al. Induced sputum to assess airway inflammation: a study of reproducibility. Clin Exp Allergy 1997; 27: 1138-1144.

18. Hirvonen M-R, Ruotsalainen M, Roponen M, et al. Nitric oxide and proinflammatory cytokines in nasal lavage fluid associated with symptoms and exposure to building microbes. Am J Respir Crit Care Med 1999; 160: 19431946.

19. Hamid Q, Springall DR, Riveros-Moreno V, et al. Induction of nitric oxide synthase in asthma. Lancet 1993; 342: $1510-1513$.

20. Robbins RA, Barnes PJ, Springall DR, et al. Expression of inducible nitric oxide in human lung epithelial cells. Biochem Biophy Res Commun 1994; 203: 209-218.

21. Shaul PW, North AJ, Wu LC, et al. Endothelial nitric oxide synthase is expressed in cultured human bronchial epithelium. J Clin Invest 1994; 94: 2231-2236. 